\title{
Communicating (and Responding to) Sexual Health Status: Reasons for STD (Non) Disclosure
}

\author{
Tara M. Emmers-Sommer ${ }^{1}$, Kathleen M. Warber ${ }^{2}$, Stacey Passalacqua ${ }^{3}$, Angela Luciano ${ }^{3}$ \\ ${ }^{1}$ Department of Communication Studies, University of Nevada, Las Vegas, USA; ${ }^{2}$ Wittenberg University, Springfield, USA; ${ }^{3}$ Department \\ of Communication, University of Arizona, Tucson, USA. \\ Email: tara.emmerssommer@unlv.edu
}

Received May $18^{\text {th }}$, 2010; revised July $3^{\text {rd }}$, 2010; accepted July $6^{\text {th }}, 2010$.

\begin{abstract}
This investigation examines the sexual health status of individuals and their attitudes toward STDs and STD disclosure (and reasons for nondisclosure) and response. In doing so, this study provides insight into young adults' sexual practices, attitudes, and behaviors. Two-hundred fifty-three adults of varying relational status participated in an online study about sexual health status, sexual health knowledge, sexual behaviors, relational factors, responses to STD disclosure, reasons for nondisclosure, and if circumstances under which a STD was acquired affected partners' reaction to the disclosure. Results indicated that, although undergraduate students are knowledgeable about safer sex practices and are concerned about STDs and birth control, few "always" practice safer sex. When considering relational status, STD status and disclosure of that status becomes complicated. However, findings of this investigation suggest that potential positive responses to a perceived negative disclosure (i.e., a positive STD status) are possible when certain relational factors exist and the circumstances surrounding the acquisition of the STD involve more external (e.g., didn't know prior partner had STD) versus internal locus (e.g., partner engaged in risk behavior) of control factors.
\end{abstract}

Keywords: STDs, Self-Disclosure, Sexual Health, Condom Use, Safer Sex

\section{Introduction}

Much research exists on HIV and AIDS [1]. Similarly, much research exists on actual versus perceived knowledge about STDs [2]. Within the extant communication literature, little research exists regarding individuals communicating reasons for (not) disclosing a positive STD status and the reception of such a disclosure. Clearly, communicating about one's sexual health status and feeling comfortable doing so are of value as such communication adds to our repertoire of knowledge about safer sex, safer sexual communication as well as the safety of the self and others.

According to Emmers-Sommer and Allen [1], "safer sex is "any action a person takes to diminish the level of risk for HIV infection". This definition can also be applied to reducing the risk of STD infection. Safer sex is most often used to describe condom use during sexual behavior to prevent contact with bodily fluids. Other sexual behaviors exist that are deemed "safer" than others. For example, engagement in mutual masturbation vs. anal sex or engagement in oral sex (which does carry some degree of risk) vs. engagement in vaginal sex are both considered to be safer sex practices. One can also reduce his or her STD or HIV risk by reducing the number of sexual partners and engaging in sexual behavior with partners who don't carry increased risk factors (e.g., IV drug use, multiple partners, prostitution). Understanding a partner's risk factors, however, necessitates that individuals engage in candid discussions with the partner as well as be open and honest about their own sexual health.

\subsection{Barriers to Disclosure of Sexual Health Status}

Unfortunately, many individuals perceive candid sexual discussions as inappropriate and telling or asking about such information as "nobody's business". Engagement in such discussions is deemed taboo by many and as an expectancy violation. Asking about another's sexual practices and health might be deemed offensive. Similarly, engagement in such disclosures about the self might arouse suspicions in a potential partner. According to Lucchetti [3], deceptive disclosure practices about 
sexual history or sexual health status is not uncommon due to the fear that disclosure of information would reduce the likelihood of sex with a partner. According to the author, $1 / 5$ of respondents report misrepresenting their personal sexual history to partners. Disclosing one's own sexual history or being willing to openly hear that of a partner requires a variety of personal attributes, such as courage, willingness to have an open mind, and willingness to be nonjudgmental, among others. Indeed, for some, sexual history disclosure can cause embarrassment or threaten the relationship [4].

\subsection{Sexual Script Theory}

Sexual script theory [4-7] examines how individuals' scripts for sexual attitudes and behavior are acquired, shaped, reshaped, renegotiated, and enacted in relationships. Sexual scripts are influenced at cultural, interpersonal, and intrapsychic levels [5-7].

\subsection{Cultural Scripts}

Strongly influenced by the media, cultural scripts are the broadest of the three levels of sexual scripts and constitute overall schemas of sexual behavior at the social level [4]. Cultural scripts involve ascertaining which partner is appropriate to desire and pursue sexually, which type of relationship between the sexual partners is appropriate, when/where partners should engage in sexual activity, and how partners are supposed to feel in relation to the engagement in the sexual activity. These schemas contribute to how individuals are supposed to behave and make sense of their experiences [5-7].

\subsection{Intrapsychic Scripts}

Intrapsychic scripts constitute "individual desires, motives, and actions that create and sustain sexual arousal" [4]. Hynie, Lydon, Cote and Wiener [8] contended that the internalization of intrapsychic scripts affects how interpersonal scripts are carried out. Intrapsychic scripts reflect a person's desires and his/her expectations about social interaction.

\subsection{Interpersonal Scripts}

Individuals' experiences and sexual and relational histories affect their interpersonal scripts [8]. Interpersonal scripts are created by an individual's interpretation of the cultural script and their internalization of their intrapsychic script [4]. Hynie et al. [8] contended, "In other words, rehearsal of interpersonal scripts derived from cultural scenarios actually shapes individual attitudes, values and beliefs and, in this manner, interpersonal scripts act as the link between individual attitudes and societal norms”. Sexual scripts involve the need to create routine and recognizable patterns of behavior so parties involved in a sexual act know what actions are expected or required. Sexual practices become episodes that are negotiated between or among individuals. Each participant needs to recognize his or her role in the script as well as others' roles. Actions that fall outside of the script can be construed as expectancy violations [1]. This contention is important as it relates to sexual behavior and disclosure of sexual attitudes, sexual history, and sexual health status. Specifically, many individuals would consider asking someone about risk behaviors to be non-normative and outside of an appropriate script. Thus, individuals experience anxiety and pressure to engage in normative scripted communication behaviors and sexual behaviors, even if doing so constitutes a relational or health risk for the individual and partner. This anxiety and fear of being viewed negatively or as deviant is further compounded by the individual's personal knowledge of having a STD and disclosing it to a partner or potential partner. As noted earlier, the anxiety felt over anticipated negative reaction and rejection could lead some individuals to engage in deception about their sexual health status [4]. This aforementioned review leads to the following research questions:

RQ1: What is the sexual health status profile of participants?

RQ2a: How concerned are participants about HIV, STDs, and pregnancy?

RQ2b: What sexual health issue is most concerning to participants?

RQ3: How knowledgeable are participants about birth control and condom use?

RQ4: What are participants' attitudes about condom use?

RQ5: When is the appropriate time (e.g., upon first meeting, before first having sex) to disclose one's having a STD?

RQ6: What reasons do participants provide for why an individual who knowingly has a STD to not disclose it to a partner?

RQ7: How do participants respond to a partner's STD disclosure?

RQ8: Does how a participant's partner contracted a STD affect reaction to the disclosure?

\section{Method}

\subsection{Instruments}

Some of the informational questions used in this study were derived from the Henry J. Kaiser Family Foundation's National Survey of Adolescents and Young Adults: Sexual Health Knowledge, Attitudes and Experiences [9] Several additional questions were added by the authors as well as the implementation of the condom use selfefficacy scale [10]. Reliability and descriptive information regarding this scale is reviewed below.

Condom-use Self-efficacy Scale. Undergraduate stu- 
dents' condom self-efficacy was measured using Brafford and Beck's [10] Condom-use Self-efficacy Scale. Items for this scale were originally gleaned from three sources: an expert panel, previous literature, and input from students themselves. From these sources, 15 factors were identified as they related to college students' selfefficacy with condom use. The authors then created 28 self-efficacy items to cover the breadth and depth of the 15 factors. Each item is measured on a 1-5 scale $(1=$ strongly disagree, 5 = strongly agree), with several reverse-scored items. Brafford and Beck [10] reported a 0.91 (Cronbach's $\alpha$ ) for the measure. With the present sample, reliability was an acceptable 0.91 (Cronbach's $\alpha$ ).

\subsection{Procedures}

Individuals who participated in this study completed an online survey. All participants for this study were enrolled in various undergraduate communication courses at a large, southwestern university. The authors believed it appropriate to target undergraduate students as the population of interest given the degree of sexual activity and number of sexual partners among this population. Solicitation for students occurred in a number of fashions. First, certain classes were assigned to the researchers for participant solicitation. If the course instructor had a course webpage, then the link to the online survey was posted on the course webpage. Because the webpage was password protected, only students enrolled in those courses - and who wished to participate in the studycould access the survey link. In the event a course did not have a webpage, the researchers visited the class and wrote the online survey link on the blackboard for students who wished to participate. Individuals who participated in the study read an online disclaimer, explaining the nature of the study, and agreed to the terms of the study, including that they were at least 18 years of age and realized that they would be asked questions that were relational and sexual in nature. Given the survey was conducted online, participants completed the survey confidentially. No names were taken at any time. Upon completing the survey, participants clicked a "submit" button which submitted their survey responses to a CGI bin. Participants received a receipt to print and submitted the receipt to their respective instructor to receive extra credit.

\subsection{Sample}

Two-hundred fifty three $(n=253)$ individuals partici- pated in this study, of which 152 reported being women, 64 reported being men, and 37 did not report their sex. Of the 253 participants, 166 reported currently being in a relationship. Of the male participants currently in a relationship, 96\% reported that they were in a heterosexual relationship. Of the female participants currently in a relationship, 95.5\% reported that they were in a heterosexual relationship. Regarding relationship status, 54 individuals reported that they were casually dating, 100 reported that they were seriously dating, 3 reported that they were engaged, 9 reported that they were married, 51 reported that they were not currently in a relationship, and 36 did not answer the question. Of those currently involved in a relationship, the average relationship length was 15.64 months, with relationship length ranging from less than one month to 13 years. Of those currently involved in a relationship, $84.8 \%$ reported that they were sexually active within their relationship. Of those individuals who were sexually active, $74.8 \%$ reported that their relationship was monogamous, $17 \%$ reported that it was non-monogamous, and $8.2 \%$ reported that they didn't know if their relationship was monogamous or not. Similarly, $75.9 \%$ of the participants reported practicing safer sex (e.g., condom use) whereas $24.1 \%$ reported that they did not practice safer sex. Interestingly, however, follow-up questions on specific sexual acts and condom use indicated a bleaker picture of safer sexual practices. Specifically, participants were asked to rate their condom usage on a scale of $1=$ never to $5=$ always in regard to various sexual acts. Results are indicated in Table 1.

RQ1 asked, "What is the sexual health status profile of participants?" Of all participants in the sample, 47.9\% reported having been tested for HIV and other STDs and 52.1\% reported not having been tested. Participants who did get tested were asked to report why they had been tested. Three reported doing so because they were experiencing symptoms, 72 reported doing so just for their own information - to be "on the safe side," three reported getting tested because a former partner had informed them of tested positive for a STD, 41 reported being tested at the suggestion of their physician, 9 reported being influenced by the media to get tested, and 7 reported being influenced by friends to get tested. Other reasons reported for getting tested included experience with prostitutes, military requirement, to be put on birth control, being sexually active in the past, and as a basis for employment (each incidence reported once). Partici-

Table 1. Undergraduate students' reporting of safer sexual practice by sexual act

\begin{tabular}{|c|c|c|c|c|c|}
\hline & Never & Rarely & Sometimes & Almost Always & Always \\
\hline If I have vaginal sex, I use a condom & $9.8 \%$ & $11.1 \%$ & $20.9 \%$ & $27.8 \%$ & $30.3 \%$ \\
\hline $\begin{array}{l}\text { If I have oral sex, I use a condom (to perform oral sex on a man) or a } \\
\text { dental dam to perform oral sex on a woman) }\end{array}$ & $83.5 \%$ & $5.1 \%$ & $5.1 \%$ & $3.0 \%$ & $3.4 \%$ \\
\hline If I have anal sex, I use a condom & $31.1 \%$ & $3.8 \%$ & $11.8 \%$ & $10.8 \%$ & $42.5 \%$ \\
\hline
\end{tabular}


pants were asked if they had ever had an STD and 7.8\% reported "yes," 81.6\% reported "no," and 10.6\% reported "don't know". Two participants reported having herpes, 2 reported having gonorrhea, 4 reported having chlamydia, 9 reported HPV, and one reported having HPVgenital warts. Participants were asked if their current relational partner had an STD. Of those participants currently in a relationship, $3 \%$ reported that their partner had an STD, 83.4\% reported that their partner did not have an STD, $12.8 \%$ reported that they didn't know if their partner had an STD or not, 4 reported that it was a "nonissue," and 2 did not answer the question. All participants were asked to report if any past partner, to their knowledge, had an STD. Of those answering the question, $5.6 \%$ reported "yes," $73.5 \%$ reported "no," $20.9 \%$ reported that they "didn't know" and 38 participants didn't answer the question.

RQ2a and b asked, "How concerned are participants about HIV, STDs, and pregnancy" and "What sexual health issue is most concerning to participants?" For those answering the questions, $75.9 \%$ reported that HIV, STDs, and pregnancy were "A very big concern," $15.3 \%$ reported that it was "A somewhat big concern," 6.9\% reported that it was "Not much of a concern," $1.4 \%$ reported that it was "Not a concern at all," and $0.5 \%$ reported "Don't know". Participants most often reported that HIV was most concerning to them (48.6\%), followed by pregnancy (34.4\%), and $17 \%$ reported that they were most concerned by STDs (gonorrhea, syphilis, genital warts, chlamydia, herpes).

RQ3 asked, "How knowledgeable are participants about birth control and condom use?" Results are reported in Table 2.

RQ4 asked, "What are participants' attitudes about condom use?” Results are reported in Table 3.

RQ5 asked, "When is the appropriate time (e.g., upon first meeting, before first having sex) to disclose one's having a STD?” Results are reported in Table 4.

For RQs 6-8, a coder coded all of the responses. Using procedures similar to Emmers and Canary [11]), responses were placed into categories derived by theme. When a response did not fit a category, a new category was formed. A second coder served as a reliability check for a random $20 \%$ of the responses for each question. Reliability for RQ6-RQ8 were 0.88, 0.96, and 0.96 (Cohen's kappa), respectively.

RQ6 asked, "What reasons do participants provide for why an individual who knowingly has a STD to not disclose it to a partner? Results are reported in Table 5.

RQ7 asked, "How do participants respond to a partner's STD disclosure?” Results are reported in Table 6.

RQ8 asked, "Does how the participant's partner contracted a STD affect reaction to the disclosure?” Results are reported in Table 7.

\section{Discussion}

The purpose of this investigation was to examine sexual health status, concerns, and reasons to disclose (and not disclose) STD status and response to such disclosures. Results of this investigation indicate that undergraduate students are, indeed, concerned about STDs and HIV, have positive attitudes about condom use, and are knowledgeable about HIV and STD transmission. Nevertheless, only 30\% report "always" wearing a condom during vaginal sex. And, despite the fact that HIV can be transmitted via anal or oral sex, only 3.4\% report using a condom or dental dam when having oral sex and $42.5 \%$ report using a condom when having anal sex. This finding is not uncommon as many individuals, while knowledgeable about HIV, AIDS and other STDs, often do not practice safer sex. Often, individuals believe that they are not vulnerable to STD or HIV acquisition and this impression grows as the relationship does. Specifically, as relationships develop and trust increases, condoms are often abandoned for alternative forms of birth control. This finding is consistent with Metts and Fitzpatrick's [4] contention that as relationships develop individuals seek out alternative forms of birth control.

A strong contribution of this investigation is that it examined students' perceptions of when it was the appropriate time to disclose a positive STD status to a partner, reasons for not doing so, how one might react to the disclosure, and if the circumstances under which the STD was contracted affected reaction to the disclosure. Findings indicated that most individuals felt it was appropriate to inform the partner of a positive STD status

Table 2. Undergraduate students' knowledge about birth control and condom use (\%)

\begin{tabular}{|c|c|c|c|c|c|}
\hline & $\begin{array}{l}\text { Very } \\
\text { Effective }\end{array}$ & $\begin{array}{l}\text { Somewhat } \\
\text { Effective }\end{array}$ & $\begin{array}{l}\text { Not too } \\
\text { Effective }\end{array}$ & $\begin{array}{l}\text { Not at all } \\
\text { Effective }\end{array}$ & $\begin{array}{l}\text { Don't } \\
\text { Know }\end{array}$ \\
\hline How effective are birth control pills in preventing pregnancy? & $56.2 \%$ & $39.6 \%$ & $.9 \%$ & $0 \%$ & $3.2 \%$ \\
\hline How effective are birth control pills at preventing HIV/AIDS? & $9 \%$ & $1.8 \%$ & $3.7 \%$ & $90.4 \%$ & $3.2 \%$ \\
\hline $\begin{array}{l}\text { How effective are birth control pills at preventing other STDs } \\
\text { (gonorrhea, syphilis, genital warts, chlamydia, herpes)? }\end{array}$ & $.5 \%$ & $2.8 \%$ & $2.3 \%$ & $90.4 \%$ & $4.1 \%$ \\
\hline How effective are condoms at preventing pregnancy? & $32.1 \%$ & $64.2 \%$ & $.9 \%$ & $1.4 \%$ & $1.4 \%$ \\
\hline How effective are condoms at preventing HIV/AIDS? & $28.1 \%$ & $47.5 \%$ & $12.4 \%$ & $7.8 \%$ & $4.1 \%$ \\
\hline $\begin{array}{l}\text { How effective are condoms at preventing other STDs (gonorrhea, } \\
\text { syphilis, genital warts, chlamydia, herpes)? }\end{array}$ & $19.3 \%$ & $53.2 \%$ & $16.1 \%$ & $6.9 \%$ & $4.6 \%$ \\
\hline
\end{tabular}


Table 3. Undergraduate students' attitudes about condoms (\%)

\begin{tabular}{|c|c|c|c|c|c|}
\hline & $\begin{array}{l}\text { Strongly } \\
\text { Agree }\end{array}$ & $\begin{array}{l}\text { Somewhat } \\
\text { Agree }\end{array}$ & $\begin{array}{l}\text { Somewhat } \\
\text { Disagree }\end{array}$ & $\begin{array}{l}\text { Strongly } \\
\text { Disagree }\end{array}$ & $\begin{array}{l}\text { Don’t } \\
\text { Know }\end{array}$ \\
\hline It is not a big deal to have sex without a condom once in a while & $4.9 \%$ & $23.1 \%$ & $24.7 \%$ & $46.6 \%$ & $8 \%$ \\
\hline $\begin{array}{l}\text { Unless you have a lot of sexual partners, you don't need to use } \\
\text { condoms }\end{array}$ & $2.4 \%$ & $10.9 \%$ & $15.8 \%$ & $70.4 \%$ & $.4 \%$ \\
\hline Buying condoms is embarrassing & $4.9 \%$ & $26.9 \%$ & $22.9 \%$ & $40.4 \%$ & $4.9 \%$ \\
\hline Condoms break a lot & $4.5 \%$ & $31.8 \%$ & $31.0 \%$ & $20.0 \%$ & $12.7 \%$ \\
\hline It is hard to bring up the topic of condoms & $2.0 \%$ & $10.9 \%$ & $27.9 \%$ & $53.8 \%$ & $5.3 \%$ \\
\hline Sex without a condom isn't worth the risk & $46.5 \%$ & $27.3 \%$ & $17.6 \%$ & $6.9 \%$ & $1.6 \%$ \\
\hline $\begin{array}{l}\text { If my partner suggested using a condom, I would feel like my } \\
\text { partner cared about me }\end{array}$ & $46.1 \%$ & $34.6 \%$ & $8.2 \%$ & $3.7 \%$ & $7.4 \%$ \\
\hline If my partner suggested using a condom, I would feel relieved & $45.1 \%$ & $33.7 \%$ & $9.3 \%$ & $4.1 \%$ & $7.7 \%$ \\
\hline $\begin{array}{l}\text { If my partner suggested using a condom, I would feel like my } \\
\text { partner respected me }\end{array}$ & $51.0 \%$ & $32.2 \%$ & $7.8 \%$ & $2.4 \%$ & $6.5 \%$ \\
\hline If my partner suggested using a condom, I would feel insulted. & $1.2 \%$ & $4.5 \%$ & $12.6 \%$ & $76.4 \%$ & $5.3 \%$ \\
\hline $\begin{array}{l}\text { If my partner suggested using a condom, I would be suspicious or } \\
\text { worried about his/her past sexual history }\end{array}$ & $1.2 \%$ & $22.0 \%$ & $25.2 \%$ & $47.2 \%$ & $4.5 \%$ \\
\hline $\begin{array}{l}\text { If my partner suggested using a condom, I would feel like my } \\
\text { partner was suspicious or worried about my past sexual history }\end{array}$ & $2.4 \%$ & $16.3 \%$ & $26.5 \%$ & $48.2 \%$ & $6.5 \%$ \\
\hline $\begin{array}{l}\text { If my partner suggested using a condom, I would be glad my } \\
\text { partner brought it up }\end{array}$ & $42.3 \%$ & $42.7 \%$ & $9.3 \%$ & $2.4 \%$ & $3.3 \%$ \\
\hline $\begin{array}{l}\text { If my partner suggested using a condom, I would feel like s/he is } \\
\text { being responsible }\end{array}$ & $65.0 \%$ & $26.4 \%$ & $4.5 \%$ & $1.6 \%$ & $2.4 \%$ \\
\hline
\end{tabular}

Table 4. Appropriate time in a relationship to disclose a positive STD status

\begin{tabular}{|c|c|c|c|c|c|}
\hline & & \multicolumn{3}{|c|}{ At what point in a relationship should someone reveal s/he has an STD? } & \multirow{2}{*}{ Tota } \\
\hline & & When they meet the partner & Before they first have sex & Not obligated to tell & \\
\hline \multirow[t]{4}{*}{ Relational Status } & Casually dating & 5 & 43 & 1 & 49 \\
\hline & Seriously Dating & 7 & 91 & 0 & 98 \\
\hline & Engaged & 0 & 3 & 0 & 3 \\
\hline & Married & 4 & 4 & 0 & 8 \\
\hline Total & & 20 & 186 & 2 & 208 \\
\hline
\end{tabular}

Table 5. Reported reasons for not disclosing a positive STD status to a partner

\begin{tabular}{|c|c|c|}
\hline Reason & Example & $\mathrm{n}$ \\
\hline Ashamed & "Too ashamed to say anything" & 12 \\
\hline Embarrassed & “Felt too embarrassed” & 110 \\
\hline Knowledge & “Didn’t know they are infected” & 5 \\
\hline No reason & "There is no reason to tell" & 27 \\
\hline Other & "Wants to get to know the other first," "Might be breaking up soon" & 24 \\
\hline Rejection by partner & “Afraid of rejection,” “Don’t want to be loved less” & 104 \\
\hline Selfish & “Greed,” "Selfishness,” "If they are a jerk and want to infect partner” & 25 \\
\hline Transmission & "If they weren't sexually active," "they might have an STD that cannot be transmitted to another" & 26 \\
\hline
\end{tabular}

prior to first having sex. This finding is interesting because although "when we first meet" was a choice option, few chose it. This finding is consistent with what sexual script theory argues, as many perceive revealing a positive STD status to be an inappropriate disclosure early on in a relationship. Implications exist for the timing of the disclosure, as an early admittance might quash the poten- tial for the relationship to develop. That said, waiting until the relationship has developed such that sexual, intimate contact is perceived as appropriate also holds implications. Specifically, one must now balance a negative or a potentially negative disclosure with the positive feelings felt for and by the partner. As indicated by the findings, the circumstances under which a partner con- 
tracted an STD mattered to many participants. Specifically, if the STD was contracted via behaviors that are perceived as risky or irresponsible (e.g., IV drug use, prostitution, cheating), individuals were less tolerant of those infection conditions. Results indicate, however, that if the partner contracted the STD unknowingly (e.g., an infected partner in his/her past did not inform him/her) or as the result of a past, serious relationship, then individuals might accept the STD disclosure more compassionately or acceptingly. This is important information as it assists in our understanding about the potential effect of health status disclosures on partners and that certain conditions surrounding the nature of the disclosure could possibly ameliorate negative feelings.

Participants provided many reasons for why individuals might not want to disclose a positive STD status, with the two most prominent reasons being "embarrassment" and "fear of rejection". This information is important for a variety of reasons. First, results of this investigation indicate that individuals want to know their partner's STD status prior to having sex. Yet, the participants were also able to provide over 300 reasons why someone might not want to disclose that information. What is suggested by the findings is that if individuals felt that they could disclose their positive STD status in a safe and understanding relational environment such that the likelihood of feeling embarrassment or rejection was reduced, the likelihood of disclosure could increase. Timing of the disclosure is complicated. From a sexual script theory perspective, mentioning this type of information early in a relationship is more frowned upon than in more advanced relationships as "sex talk" is considered to be inappropriate and deviant in a relationship's infancy. Yet, making a STD disclosure in an advanced relationship can also be perceived negatively for a variety of reasons. For one, if an individual entered into a relationship knowing s/he had a STD, his/her partner would have likely expected this information to have been part of past discussion in a close, committed relationship. Further, if a partner acquired the STD after the relationship had been established, it is again perceived as a transgression, as it suggests engagement in risk behavior (e.g., infidelity, IV drug use). Both circumstances suggest a transgression took place [12], but in different fashions.

\section{Implications}

Numerous positive implications exist from the results of this investigation; information that holds practical implications for sexual communication skills training, sexual education programs, and counseling. Indeed, safer sexual communication skills training and sexual education are valuable and essential from a preventative standpoint. And, in a best case scenario, individuals would engage in safer sexual communication and safer sexual practices with their partner. However, we recognize that this is often not the case for myriad reasons. For example, partners could use poor judgment, deception, or "let things get out of hand”. Even with the best of intentions, partners could be unaware of their STD status or experience condom failure (e.g., breakage, leaking). It is important to consider individuals who might be experiencing a sense of hopelessness due to mistakes, poor judgment, or lack of information. Indeed, as indicated by these results, it is not uncommon for someone with a positive STD status to feel like "damaged goods" and fear disclosing their status to a partner or potential partner out of fear of rejection or embarrassment. Valuably, this study demonstrates that a partner or potential partner might be more receptive, understanding and compassionate than an individual might have anticipated when receiving a disclosure about a positive partner STD status. As mentioned

Table 6. Responses to a partner's STD disclosure

\begin{tabular}{ll}
\hline Response & $\mathrm{n}$ \\
\hline Shocked/surprised & 34 \\
Negative emotions (angry, sad, upset) & 69 \\
Glad s/he told me/respect honesty/be supportive & 26 \\
Stop having sex & 29 \\
Get tested/see a doctor & 24 \\
Be sure to use protection & 19 \\
Break up/leave partner & 32 \\
Stay/feel the same about partner & 18 \\
Learn more/ask more questions & 43 \\
Depends on the STD/how the partner contracted it & 18 \\
Depends on how much I like the person & 18 \\
Not sure & 22 \\
Other & 14 \\
\hline
\end{tabular}

Table 7. Circumstances in which STD was acquired and tolerability

\begin{tabular}{lcccc}
\hline Circumstance & \multicolumn{3}{c}{ Tolerability } \\
& Yes & No & Unsure & $\mathrm{n}$ \\
& & $\mathrm{X}$ & & 22 \\
If the partner got it from cheating & $\mathrm{X}$ & & 7 \\
$\begin{array}{l}\text { If the partner got it from gay sex } \\
\text { If the partner got it from promiscu- }\end{array}$ & $\mathrm{X}$ & & 30 \\
$\begin{array}{l}\text { ous/careless behavior } \\
\text { If the partner was lied to/situation }\end{array}$ & $\mathrm{X}$ & & & 16 \\
$\begin{array}{l}\text { was not their fault } \\
\text { If the person got it from } \\
\text { drugs/prostitution }\end{array}$ & & $\mathrm{X}$ & & 9 \\
$\begin{array}{l}\text { If the person got from a serious } \\
\text { relationship }\end{array}$ & $\mathrm{X}$ & & & 7 \\
$\begin{array}{l}\text { How long they've known they had } \\
\text { it/if they had slept with me already }\end{array}$ & & & $\mathrm{X}$ & 5 \\
$\begin{array}{l}\text { Other } \\
\text { How s/he got it/from whom }\end{array}$ & & $\mathrm{X}$ & 14 \\
\hline
\end{tabular}


above, this is noteworthy and informative to sexual skills training, sexual education programs, and counseling contexts in which sexual issues are a point of contention. What the findings of this investigation suggest is that individuals are willing to have the conversation and, under certain conditions, are more willing to be understanding, compassionate and accepting of the situation. Alternatively, results of this investigation also suggest that there are certain conditions under which an STD was acquired that partners are less understanding, accepting and compassionate (e.g., cheating, IV drug use, prostitution). This, too, is of value to scholars and practitioners. Indeed, this suggests a quandary for individuals who acquired an STD through these aforementioned means in the sense of to disclose or not disclose? From an ethical standpoint, one might argue that an individual should disclose their STD status to a partner or potential partner. That said, the results of this study suggest that making such a disclosure under certain acquisition conditions could damage the relationship with their partner. As such, individuals in these circumstances might feel discouraged from making such a disclosure. Knowing that, educators and practitioners can craft communication and relational skills training to focus on how individuals can most effectively communicate this information and how partners might best receive it.

\section{Conclusions}

Although the sample for this study included strong female representation, the study nevertheless is insightful and informative. To date, few studies have examined actual sexual health status of individuals and their attitudes toward STDs and STD disclosure (and reasons for nondisclosure) and response. This study provides insight into young adults' sexual practices, attitudes, and behaviors. What was found was that, although undergraduate students are knowledgeable about safer sex practices and are concerned about STDs and birth control, few "always" practice safer sex. Findings of this investigation suggest that potential positive responses to a perceived negative disclosure (i.e., a positive STD status) are possible when certain relational factors exist and the circumstances surrounding the acquisition of the STD involve more external (e.g., didn't know prior partner had STD) versus internal locus (e.g., partner engaged in risk behavior) of control factors.

\section{REFERENCES}

[1] T. M. Emmers-Sommer and M. Allen, "Safer Sex in Personal Relationships: The Role of Sexual Scripts in HIV Infection and Prevention,” Lawrence Erlbaum Associates, Hillsdale, 2005.

[2] D. Rouner and R. Lindsey, "Female Adolescent Communication about Sexually Transmitted Diseases," Health Communication, Vol. 19, No. 1, 2006, pp. 29-38.

[3] A. E. Lucchetti, “Deception in Disclosing One’s Sexual History: Safe Sex Avoidance or Ignorance?” Communication Quarterly, Vol. 47, No. 3, 1999, pp. 300-314.

[4] S. Metts and M. A. Fitzpatrick, "Thinking about Safer Sex: The Risky Business of 'Knowing Your Partner' Advice,” In: T. Edgar, M. A. Fitzpatrick and V. Freimuth, Ed., AIDS: A Communication Perspective, Lawrence Erlbaum Associates, Hillsdale, 1992, pp. 1-19.

[5] W. Simon and J. H. Gagnon, "Sexual Scripts," Society, Vol. 22, 1984, pp. 52-60.

[6] W. Simon and J. H. Gagnon, "Sexual Scripts: Permanence and Change,” Archives of Sexual Behavior, Vol. 15, No. 2, 1986, pp. 97-120.

[7] W. Simon and J. H. Gagnon, "A Sexual Scripts Approach,” In: J. H. Greer and W. T. O’Donohue, Ed., Theories of Human Sexuality, Plenum Publishing, New York, 1987, pp. 363-383.

[8] M. Hynie, J. E. Lydon, S. Cote and S. Wiener, "Relational Sexual Scripts and Women's Condom Use: The Importance of Internalized Norms,” Journal of Sex Research, Vol. 35, No. 4, 1998, pp. 370-380.

[9] H. J. Kaiser, T. Hoff, L. Greene and J. Davis, "National Survey of Adolescents and Young Adults: Sexual Health Knowledge, Attitudes, and Experiences,” 2003. http:// www.kff.org/youthhivstds/upload/ational-Survey-of-Adol escents-and-Young-Adults.pdf

[10] L. J. Brafford and K. H. Beck, "Development and Validation of a Condom Self-Efficacy Scale for College Students," Journal of American College Health, Vol. 39, No. 5, 1991, pp. 219-225.

[11] T. M. Emmers and D. J. Canary, "The Effect of Uncertainty Reducing Strategies on Young Couples' Relational Repair and Intimacy," Communication Quarterly, Vol. 44, No. 2, 1996, pp. 166-182.

[12] S. Metts, "Relational Transgressions,” In: W. R. Cupach and B. H. Spitzberg, Ed., The Dark Side of Close Relationships, Lawrence Erlbaum Associates, Mahwah, 1994, pp. 217-239. 